\title{
Article
}

\section{Mosapride, a 5HT-4 receptor agonist, improves insulin sensitivity and glycaemic control in patients with Type II diabetes mellitus}

\author{
N. Ueno ${ }^{1,2}$, A. Inui ${ }^{1}$, A. Asakawa ${ }^{1}$, F. Takao ${ }^{2}$, Y. Komatsu' ${ }^{2}$, K. Kotani ${ }^{3}$, R. Nishimura ${ }^{3}$, M. Kasuga ${ }^{1}$ \\ ${ }^{1}$ Division of Diabetes, Digestive and Kidney Diseases, Department of Clinical Molecular Medicine, \\ Kobe University Graduate School of Medicine, Kobe, Japan \\ ${ }^{2}$ Department of Internal Medicine, Komatsu Hospital, Neyagawa, Japan \\ ${ }^{3}$ Hyogo Institute for Clinical Research, Akashi, Japan
}

\section{Abstract}

Aims/hypothesis. We investigated the potential role of mosapride, a 5HT-4 receptor agonist, in glycaemic control in Type II (non-insulin-dependent) diabetic mellitus patients without autonomic neuropathy.

Methods. Thirty-four inpatients with Type II diabetes mellitus were randomly assigned to receive either mosapride $(5 \mathrm{mg}$ orally three times a day, $n=17$ ) or a placebo $(n=17)$ for 1 week (first study). Changes in blood glucose and insulin were determined basally as well as after intravenous glucose loading. Insulin sensitivity was evaluated during hyperinsulinaemic-normoglycaemic-clamp studies and by measuring the number of and the autophosphorylation of insulin receptors on the erythrocytes of patients $(n=9)$. Sixtynine outpatients with Type II diabetes were similarly treated with mosapride or a placebo for 8 weeks (second study). Finally, tissue- specific expression of 5HT-4 receptors was examined by reverse transcriptase-polymerase chain reaction (RT-PCR).

Results. Mosapride lowered fasting blood glucose and fructosamine concentrations $(p<0.05)$ (first study). It significantly increased the number of (Mosapride $3323 \pm 518$ vs $4481 \pm 786$ [ $p<0.05]$, Control $4227 \pm 761$ vs $3275 \pm 554$ per $300 \mu$ l erythrocytes) and the tyrosine autophosphorylation (Mosapride $3178 \pm 444$ vs $4043 \pm 651$ [ $p<0.05]$, Control $3721 \pm 729$ vs $3013 \pm 511$ insulin receptor unit) of insulin receptors, as well as glucose utilisation (Mosapride 4.92 \pm 0.53 vs $5.88 \pm 0.72$ [ $p<0.05]$, Control $4.74 \pm 0.65$ vs $4.70 \pm 0.31 \mathrm{mg} / \mathrm{kg} \cdot \mathrm{min})$. Mosapride treatment for 8 weeks significantly reduced fasting glucose $(9.91 \pm 0.34$ vs $8.51 \pm 0.34 \mathrm{mmol} / 1, p<0.05)$, insulin $(53.2 \pm 4.62$ vs $40.8 \pm 5.52 \mathrm{pmol} / \mathrm{l}, p<0.05)$ and $\mathrm{HbA}_{1 \mathrm{c}}(8.61 \pm 0.20$ vs $7.67 \pm 0.19 \%, p<0.01)$ concentrations (second study). The RT-PCR analysis demonstrated specific expression of 5HT-4 receptors in the muscle, but not in the liver or fat tissues.

Conclusions/interpretation. Mosapride could improve insulin action at muscle and glycaemic control in Type II diabetic patients. [Diabetologia (2002) 45:792-797]

Keywords Mosapride, serotonin 5HT-4 receptor, antidiabetogenic effect, insulin sensitivity, Type II diabetes mellitus, insulin receptor.
Received: 22 October 2001 / Revised: 5 February 2002

Published online: 15 May 2002

(C) Springer-Verlag 2002

Corresponding author: Dr. A. Inui, Division of Diabetes, Digestive and Kidney Diseases, Department of Clinical Molecular Medicine, Kobe University Graduate School of Medicine, 7-5-1 Kusunoki-cho, Chuo-ku, Kobe 650-0017, Japan, e-mail: inui@med.kobe-u.ac.jp

Abbreviations: 5HT, 5-Hydroxytryptamine; DTPA, diethylene triamine penta-acetic acid; NBT, nitroblue tetrazolium colorimetric test
Mosapride is a benzamide derivative which is structurally related to cisapride, which facilitates or restores motility in the gastrointestinal tract [1, 2]. Mosapride is now widely used in Japan as a prokinetic agent after extensive preclinical and clinical evaluation $[3,4,5]$. It enhanced gastric emptying of the 99mTc-DTPA liquid meal in healthy volunteers and alleviated gastrointestinal discomfort in patients with non-ulcer dyspepsia, diabetic gastroparesis, or reflex esophagitis. Agonistic action at serotonin 5HT-4 receptors and facilitation of cholinergic excitatory neurotransmission have been suggested as the mecha- 
Table 1. Clinical characteristics and effects of mosapride (Gasmotin $15 \mathrm{mg} /$ day for 1week) or a placebo on glycaemic control in inpatients with Type II diabetes

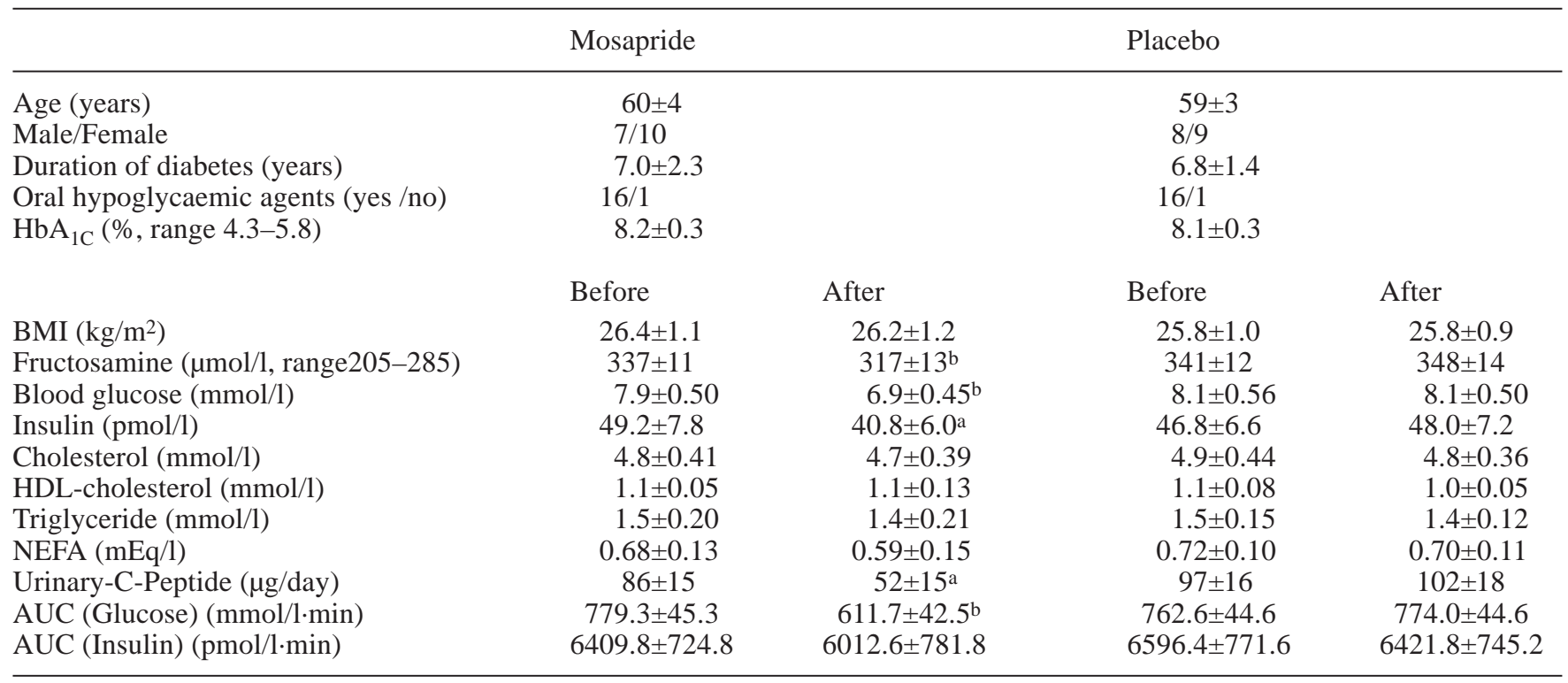

Means \pm SEM

a $p<0.05$

${ }^{\mathrm{b}} p<0.01$ vs pretreatment values

nisms by which mosapride enhances motility [6]. Mosapride is able to bind to 5HT-4 receptors of the human stomach [7]. Furthermore, mosapride has no dopamine $\mathrm{D}_{2}$ receptor antagonist activity in contrast to other gastroprokinetic agents such as cisapride and metoclopramide [2].

We have recently found that erythromycin and its derivatives, nonpeptide agonists of motilin receptors, stimulate insulin secretion from the endocrine pancreas and that 5HT-3 receptors are involved in this process $[8,9,10]$. In addition to its well known gastroprokinetic effect [11], orally administered erythromycin significantly stimulated insulin secretion and improved glycaemic control in patients with Type II diabetes mellitus [12]. Because cisapride, which acts as an agonist of both 5HT-3 and 5HT-4 receptors $[6,13]$, might also have stimulatory effects on the endocrine pancreas in humans ([14] and our unpublished data), in this study we examined mosapride, a specific 5HT4 receptor agonist, to see if it has beneficial effects on glycaemic control in patients with Type II diabetes mellitus.

\section{Subjects and methods}

First study. We studied 34 patients with Type II diabetes mellitus who were randomly assigned to receive either mosapride ( $5 \mathrm{mg}$ of mosapride citrate orally three times a day, $n=17$ ) or a placebo $(n=17)$ for 1 week (Table 1$)$. They were hospitalised at least 2 weeks before the study to rule out potential confounding influences and received weight-maintaining diets containing at least $200 \mathrm{~g}$ carbohydrate/day. To exclude the overlapping gastroprokinetic effects, the intravenous glucose loading test $(0.2 \mathrm{~g} / \mathrm{kg}$ body weight $)$ was done to evaluate insulin secretion before the treatment and on the last day of the treatment. Insulin sensitivity was measured during hyperinsulinaemic-normoglycaemic-clamp studies performed after short-term normalization of the blood glucose concentra$\operatorname{tion}(n=9)$ [15]. Insulin (1.56 $\mathrm{mU} / \mathrm{kilogram} \cdot \operatorname{minute})$ was infused for $4 \mathrm{~h}$ before and on the last day of the treatment with mosapride or the placebo. Blood glucose concentration was kept at $5.32 \mathrm{nmol} / \mathrm{l}$. Glucose utilisation was calculated during the last $30 \mathrm{~min}$ of the insulin infusion. The enzyme-linked immunosorbent assay was also used to evaluate insulin sensitivity by measuring the number of and the tyrosine autophosphorylation of insulin receptors on the erythrocytes of patients before and on the last day of the treatment $(n=9)$ [16].

Second study. Another 69 patients with Type II diabetes were treated similarly with mosapride $(5 \mathrm{mg}$ orally three times a day, $n=34)$ or a placebo $(n=35)$ for 8 weeks at the outpatient clinic (Table 2 ). Because we observed no apparent side effects at 8 weeks, we continued to treat the patients who agreed to enter the long term study $(n=36)$ for 24 weeks.

All patients in the first and the second studies were being treated without insulin. The hypoglycaemic agents used were mostly sulphonylureas (glibenclamide or gliclazide, $n=31$ and $n=60$ in the first and second studies, respectively) and in a few patients voglibose ( $n=3$ and 5 in the first and second studies, respectively). These drugs were given at the same doses during all of the studies. No patient received biguanides or thiazolidinediones. They were instructed to follow their weight-maintaining diets at least 2 weeks before the study and during the study. None of the patients had impaired renal function, autonomic neuropathy, or proliferative retinopathy. All patients gave informed consent to participate in the study, which had been approved by Komatsu Hospital's ethics committee.

Measurement. Blood samples from the fasting subjects were taken from an indwelling venous catheter before, during, and after the treatment for measurement of blood glucose, fructos- 
Table 2. Clinical characteristics and effects of mosapride (Gasmotin $15 \mathrm{mg} /$ day for 8 weeks) or a placebo on glycaemic control in outpatients with Type II diabetes

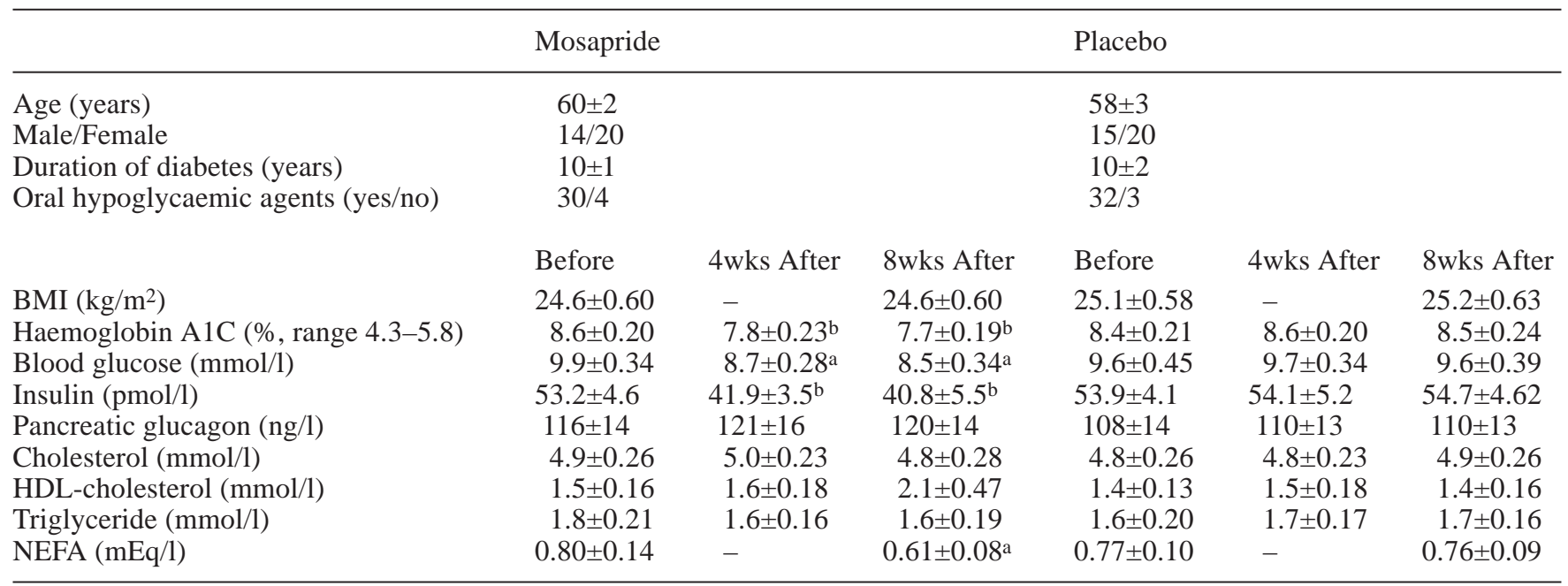

Means \pm SEM

${ }^{\mathrm{a}} p<0.05$

${ }^{\mathrm{b}} p<0.01$ vs pretreatment values
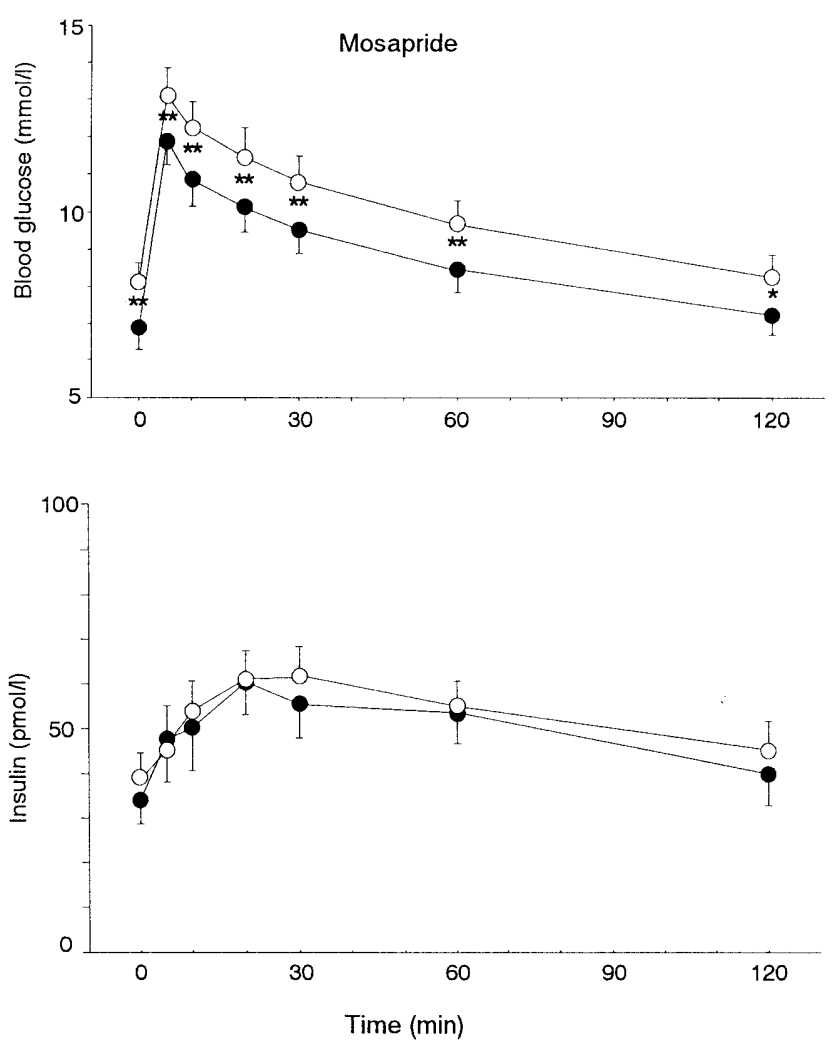

Fig. 1. Effect of mosapride treatment (Gasmotin $15 \mathrm{mg} /$ day/1 week, $n=17)$ or a placebo $(n=17)$ on blood glucose and insulin responses to intravenous glucose loading $(0.2 \mathrm{~g} / \mathrm{kg}$ body weight) in Type II diabetic patients. Glucose tolerance test was performed before the treatment $(\bigcirc-\bigcirc)$ and on the last day of the treatment $(-)$. ${ }^{*} p<0.05, * * p<0.01, * * * p<0.005$ between the two tests
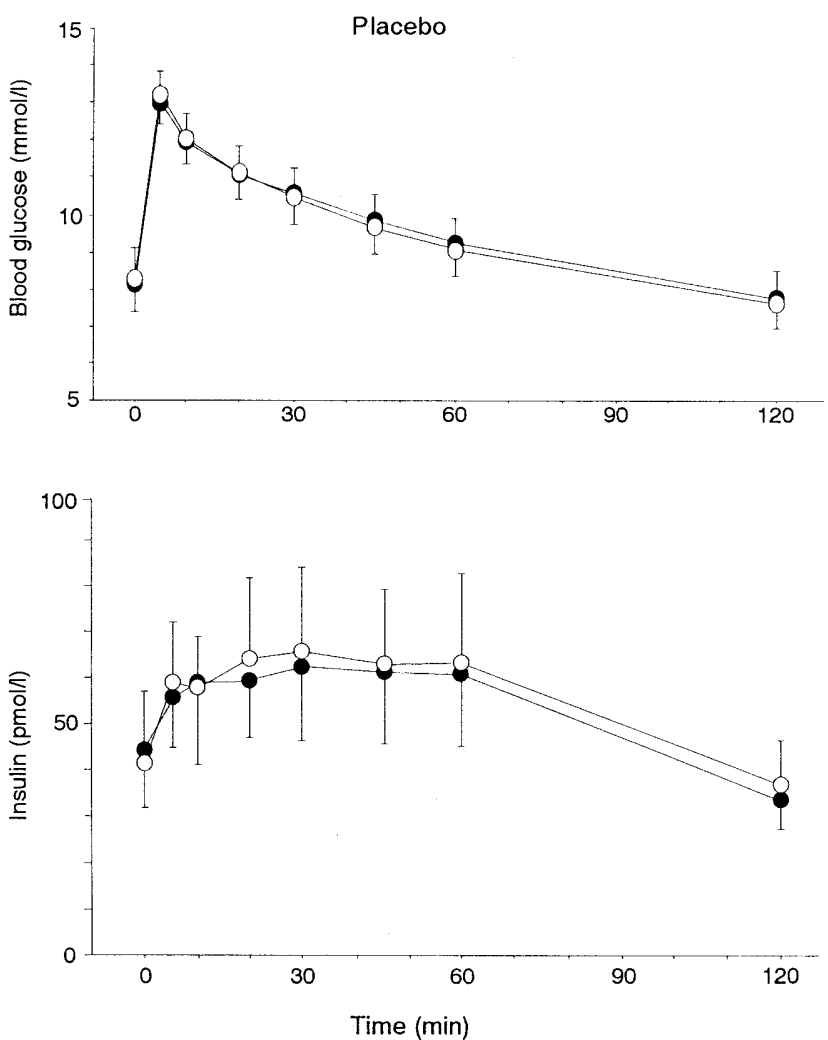

amine, and $\mathrm{HbA}_{1 \mathrm{C}}$, as well as glucose and insulin responses to intravenous glucose loading or during the clamp studies (first study). Blood was collected in tubes containing $1.2 \mathrm{mg}$ EDTA and 400KIU aprotinin (Trasylor, Bayer A-G, Leverkusen, Germany). Plasma obtained by centrifugation was stored at $-40^{\circ} \mathrm{C}$ until assayed. Blood glucose was determined by the glucose oxidase method, fructosamine by the nitroblue tetrazolium colorimetric test (NBT) method, and $\mathrm{HbA}_{1 \mathrm{C}}$ by the HPLC method. Plasma insulin and urinary C-peptide were measured with commercially available kits, Insulin-III (Boehringer-Mannheim, Mannheim, Germany) [10] and C-peptide Kit (Daiichi, 
Tokyo, Japan), respectively. Pancreatic glucagon was measured using a previously described assay [17].

Reverse transcriptase-polymerase chain reaction (RT-PCR) was performed to examine the expression of 5HT-4 receptors by using poly A RNAs from the human brain, intestine, muscle, pancreas, liver and fat tissues. All of the poly A RNAs were purchased from Clontech (Tokyo, Japan) except that of the fat tissue which we prepared ourselves. All of the 5HT-4 receptor splice variants [18] were amplified using the specific primer (5'-ATGGACAAACTTGATGCTAATGTG-3') designed to the $5^{\prime}$ end and common to all isoforms, and $3^{\prime}$-end primer (5'-TAGTACATGTGTGTGGATCCATTAATGG-3'). Results are expressed as means \pm SE. Testing for significant differences was carried out with analysis of variance (StatView) followed by t-tests. A $p$-value of less than 0.05 were considered statistically significant.

\section{Results}

There were no background differences between the treatment and the placebo groups of Type II diabetic patients (first and second studies), including factors such as age, gender, BMI, oral hypoglycaemic treatment, fasting blood glucose, and $\mathrm{HbA}_{1 \mathrm{c}}$ concentrations (Tables 1 and 2). One week of treatment with oral mosapride reduced fasting blood glucose $(7.90 \pm 0.50$ vs $6.94 \pm 0.45 \mathrm{mmol} / \mathrm{l}, \mathrm{p}<0.01)$ and fructosamine $(337 \pm 11$ vs $317 \pm 13 \mu \mathrm{mol} / 1, p<0.01)$ concentrations in diabetic patients (first study, Table 1). Mosapride reduced glucose responses to intravenous glucose loading $(p<0.05-p<0.01$ at all time points, Fig. 1). However, it had no stimulatory effect on insulin secretion and conversely tended to reduce fasting insulin concentrations. Concentrations of urinary Cpeptide, which were calculated as the average over 2 days, decreased significantly after the treatment (Table $1, p<0.05$ ). Improvement in insulin sensitivity was demonstrated by the increased number of (Mosapride $3323 \pm 518$ vs $4481 \pm 786[p<0.05]$, Control $4227 \pm 761$ vs $3275 \pm 554$ per $300 \mu$ lerythrocytes) and the tyrosine autophosphorylation (Mosapride $3178 \pm 444$ vs $4043 \pm 651$ [ $p<0.05]$, Control $3721 \pm 729$ vs $3013 \pm 511$ insulin receptor unit) of insulin receptors on the erythrocytes of patients after Mosapride, but not placebo, treatment (Fig. 2). Mosapride treatment also significantly increased glucose utilisation (Mosapride $4.92 \pm 0.53$ vs $5.88 \pm 0.72[p<0.05]$, Control $4.74 \pm 0.65$ vs $4.70 \pm 0.31 \mathrm{mg} / \mathrm{kg} \cdot \mathrm{min}$ ) in hyperinsulinaemic-nomoglycaemic clamping. The concentration of plasma insulin was kept at about $600 \mathrm{pmol} / \mathrm{l}$ to suppress hepatic glucose production during the clamp studies [15].

Glycaemic control was improved in the outpatients after long-term treatment with mosapride (second study, Table 2 and Fig. 2). Significant decreases were observed in the concentrations of fasting blood glucose $(9.91 \pm 0.34$ vs $8.51 \pm 0.34 \mathrm{mmol} / \mathrm{l}, \quad p<0.05$ at 8 weeks), $\mathrm{HbA}_{1 \mathrm{c}}(8.61 \pm 0.20$ vs $7.67 \pm 0.19 \%, p<0.01$ at 8 weeks), and fasting insulin ( $53.2 \pm 4.62$ vs $40.8 \pm 5.52$ $\mathrm{pmol} / \mathrm{l}, p<0.05$ at 8 weeks), the effects of which were
A
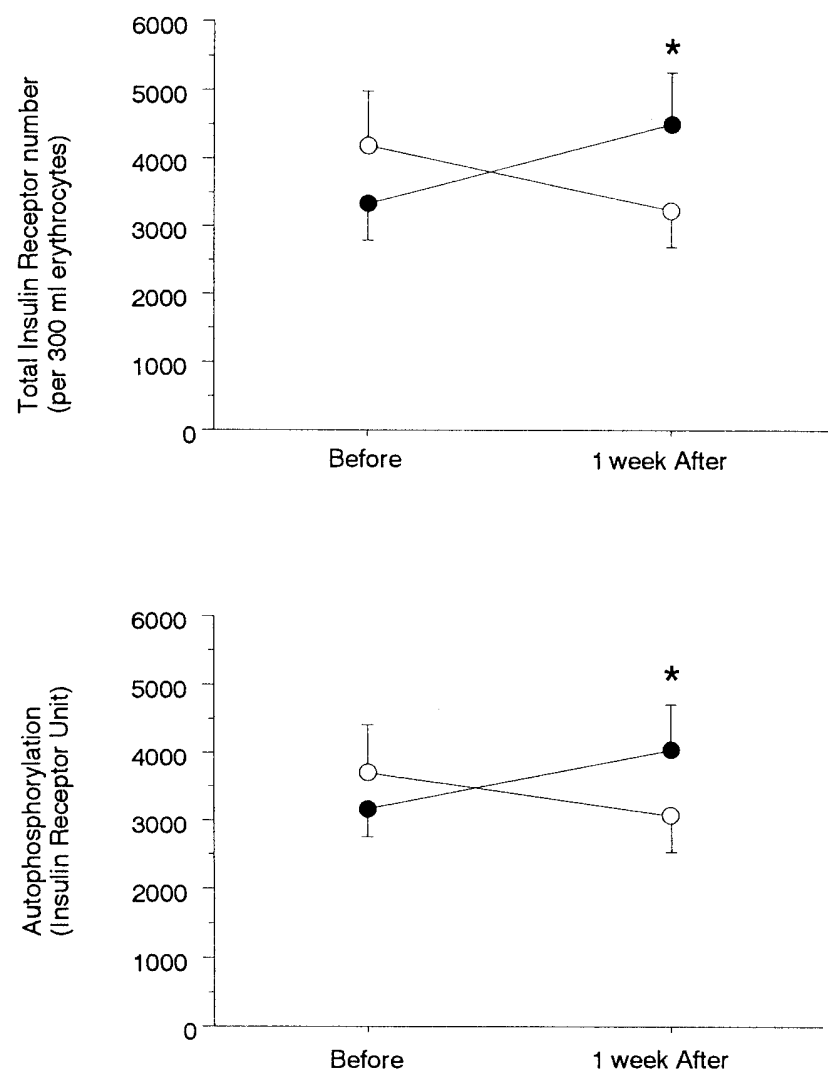

B

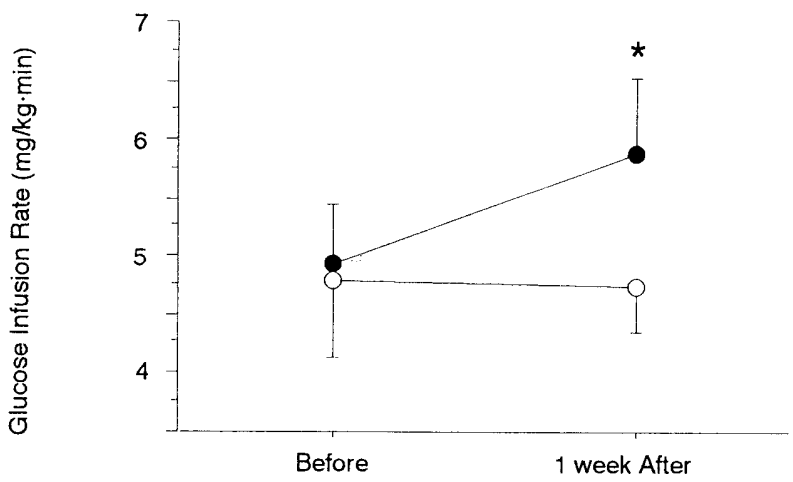

Fig. 2. Effect of mosapride treatment (Gasmotin ${ }^{\circledR} 15 \mathrm{mg} / \mathrm{day} /$ 1 week, - $n=9)$, or a placebo $(\bigcirc-\bigcirc, n=9)$ on the number of and the autophosphorylation of insulin receptors on the erythrocytes (A) or the glucose infusion rate during hyperinsulinaemic-normoglycaemic-clamp studies (B) in Type II diabetic patients. Insulin sensitivity was assessed before and on the last day of the treatment. ${ }^{*} p<0.05$ between the two tests in mosapride group

maintained for up to 6 months after the treatment (Fig. 3). Mosapride reduced plasma NEFA and triglyceride concentrations, but had no effect on pancreatic glucagon (Table 2).

Tissue specific expression of 5HT-4 receptors was examined by RT-PCR analysis. As shown in Figure 4, expression of 5HT-4 receptors was detected in the 


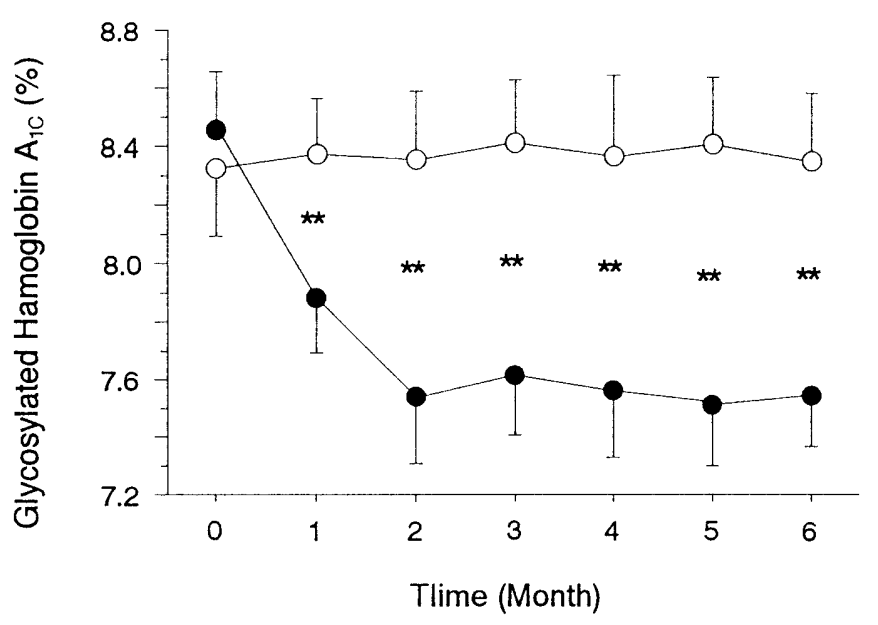

Fig. 3. Effect of long-term mosapride treatment (Gasmotin ${ }^{\circledR}$ $15 \mathrm{mg} /$ day/6 months, $-18, n=18)$, and a placebo $(\bigcirc-\bigcirc, n=$ 18) on values of glycosylated $\mathrm{HbA}_{\mathrm{lc}}$ in Type II diabetic patients. ${ }^{*} p<0.05, * * p<0.01$ between the two groups

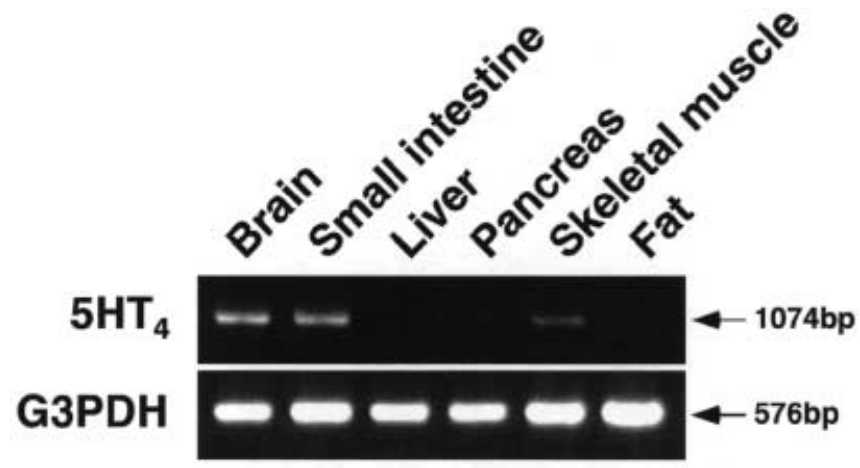

Fig. 4. Reverse transcription-PCR analysis performed with $500 \mathrm{ng}$ of mRNA from various human tissues

muscle as well as in the brain and intestine, but not in the liver and fat tissue.

There were no significant changes in body weight during mosapride therapy. There were also no side effects of mosapride administration, nor changes in the results of laboratory tests.

\section{Discussion}

In the present group of patients with Type II diabetes who were mostly receiving sulphonylureas, Mosapride treatment led to a reduction in hyperglycaemia with a simultaneous reduction in circulating insulin concentrations. The glucose-lowering effect of Mosapride was already apparent after 1 week of treatment and continued for 24 weeks. The simultaneous fall in blood glucose and insulin concentrations, as well as stronger decrease in blood glucose response to insulin after Mosapride treatment (not shown), suggested an overall improvement in insulin action. This was clearly shown in the increased glucose utilisation in the hyperinsulinaemic-normoglycaemic-clamp studies, as well as increased number of and the autophosphorylation of insulin receptors on the erythrocytes of patients after Mosapride treatment. Because erythromycin, domperidone, and metoclopramide all do not show such noticeable effects ([12] and unpublished data), it is highly likely that Mosapride directly improves insulin sensitivity, apart from its gastroprokinetic effect.

Chronic hyperglycaemia in patients with Type II diabetes occurs because of resistance to the action of insulin and decreases in insulin secretion [19]. Insulin resistance is a prominent feature in these patients and is detectable before glucose tolerance deteriorates [19]. Therefore, it is clear that pharmacological agents that improve insulin action could be of benefit in the treatment of Type II diabetes. Recently metformin and thiazolidinediones have become available [19, 20, 21]. Although their exact mechanisms of action are still not well understood, metformin primarily lowers endogenous glucose production, presumably at the level of the liver, whereas thiazolidinediones such as troglitazone increase insulin-mediated peripheral glucose disposal, which occurs predominantly in skeletal muscle [21].

The involvement of 5HT receptors in the regulation of gastrointestinal motility is well known [22, 23, 24]. However, there are few studies in the potential role of $5 \mathrm{HT}$ receptors in the secretion and/or action of insulin and other pancreatic hormones in humans [24]. Previous clinical studies showed that methysergide, which acts as a partial 5HT-1 receptor agonist and as a 5HT-2C receptor antagonist, potentiates insulin release in diabetic patients [24], and that sumatriptan, which acts as an agonist at 5HT-1P receptors on enteric neurons, inhibits insulin release in normal humans [25]. It was suggested that sumatriptan resets peripheral insulin sensitivity at muscle, liver, or adipose tissue, because it did not affect glucose homeostasis despite inhibition of insulin secretion [25]. Mosapride is a specific 5HT-4 receptor agonist because it has no affinity for at least 50 other receptors, including 5HT-1, 5HT-1A, 5HT-1B, 5HT-1D, 5HT-2, 5HT-3, 5HT-6, 5HT-7, and serotonin transporter, and because its effect on gastric motility is completely blocked by pretreatment with GR113808, a selective 5HT-4 receptor antagonist ([6, 26] and unpublished data). This study on localisation of 5HT-4 receptor mRNAs specifically in the muscle, together with the increased glucose utilisation at the clamp condition in which hepatic glucose production is thought to be suppressed [15], could suggest skeletal muscle as the site on mosapride actions. However, the exact details of how this compound improves insulin sensitivity needs to be determined.

We conclude that Mosapride is effective in decreasing plasma glucose concentrations without stimulating insulin secretion in Type II diabetic patients, with similar efficacy to troglitazone and metformin [21]. 5-HT4 receptor agonists may represent a novel class 
of insulin-sensitizing agents with no major side effects such as liver dysfunction as with troglitazone [27] and lactic acidosis as with metformin, and could be especially useful for patients with delayed gastric emptying $[10,11,12]$.

Acknowledgements. This work was supported in part by Grants-in-Aid for Scientific Research (A) 08559012 and (C) 09671057 from the Ministry of Education, Science, Sports and Culture of Japan (to A. Inui).

\section{References}

1. Yoshida N, Omoya H, Kato S, Ito T (1993) Pharmacological effects of the new gastroprokinetic agent mosapride citrate and its metabolites in experimental animals. Arzneimitte/forschung 43:1078-1083

2. Yoshida N, Kato S, Ito T (1993) Mosapride Citrate. Drugs Future 18:513-515

3. Kanaizumi T, Nakano H, Matsui Y et al. (1991) Prokinetic effect of AS-4370 on gastric emptying in healthy adults. Eur J Clin Pharmacol 41:335-337

4. Suyama T, Tokubayashi F, Ohmatsu Y et al. (1993) Accelerating effect of AS-4370 (mosapride) on gastric emptying time (double sampling test method) and its clinical efficacy on chronic gastritis accompanied by epigastric symptoms. Jpn Arch Intern Med 40:175-183

5. Hayakawa A, Kawahara K, Ueda Y, Harakawa S, Kinoshita S (1992) Clinical study of AS-4370 in non-ulcer dyspepsia: Effects of AS-4370 on upper abdominal symptoms and on hormones. J Clin Ther Med 8:639-645

6. Mine Y, Yoshikawa T, Oku S, Nagai R, Yoshida N, Hosoki K (1997) Comparison of effect of mosapride citrate and existing $5-\mathrm{HT}_{4}$ receptor agonists on gastrointestinal motility in vivo and in vitro. J Pharmacol Exp Ther 283:1000-1008

7. Sakurai-Yamashita Y, Takada K, Takemura K(1999) Ability of mosapride to bind to 5-HT4 receptor in the human stomach. Jpn J Pharmacol 79:493-496

8. Shiba Y, Mizumoto A, Satoh M, Inui A, Itoh Z, Omura S (1996) Effect of nonpeptide motilin agonist EM523 on release of gut and pancreatic hormones in conscious dogs. Gastroenterology 110:241-250

9. Suzuki H, Mochiki E, Haga N, Satoh M, Mizumoto A, Itoh Z (1998) Motilin controls cyclic release of insulin through vagal cholinergic muscarinic pathways in fasted dogs. Am J Physiol 274:G87-G95

10. Okano H, Inui A, Ueno N et al. (1996) EM523L, a nonpeptide motilin agonist, stimulates gastric emptying and pancreatic polypeptide secretion. Peptides 17:895-990

11. Janssens J, Peeters TL, Vantrappen G et al. (1990) Improvement of gastric emptying in diabetic gastroparesis by erythromycin. N Engl J Med 322:1028-1031
12. Ueno N, Inui A, Asakawa A et al. (2000) Erythromycin improves glycaemic control in patients with Type II diabetes mellitus. Diabetologia 43:411-415

13. Haga N, Suzuki H, Shiba Y, Mochiki E, Mizumoto A, Itoh Z (1998) Effect of TKS159, a novel 5-hydroxytryptamine 4 agonist, on gastric contractile activity in conscious dogs. Neurogastroenterol Mot 10:295-303

14. Funakoshi A, Shinozaki H, Miyazaki K, Nakano I, Ibayashi H (1986) Effects of cisapride on the secretion of pancreatic polypeptide in healthy volunteers. Tohoku J Exp Med 150:155-160

15. Gutniak M, Ørskov C, Holst JJ, Ahrén B, Effendic S (1992) Antidiabetogenic effect of glucagon-like peptide-I (7-36) amide in normal subjects and patients with diabetes mellitus. N Engl J Med 326:1316-1322

16. Hagino H, Shii K, Yokono K et al. (1994) Enzyme-linked immunosorbent assay method for human autophosphorylated insulin receptor. Applicability to insulin-resistant states. Diabetes 43:274-280

17. Nishino T, Kodaira T, Shin S et al. (1981) Glucagon radioimmunoassay with use of antiserum to glucagon C-terminal fragment. Clin Chem 27:1690-1697

18. Blondel O, Gastineau M, Dahmoune Y, Langlois M, Fischmeister R (1998) Cloning, expression, and pharmacology of four human 5-hydroxytryptamine 4 receptor isoforms produced by alternative splicing in the carboxyl terminus. J Neurochem 70:2252-2261

19. Saltiel AR, Olefsky JM (1996) Thiazolidinediones in the treatment of insulin resistance and type II diabetes. Diabetes 45:1661-1669

20. Schwartz S, Raskin P, Fonseca V, Graveline JF (1998) Effect of troglitazone in insulin-treated patients with type II diabetes mellitus. N Engl J Med 338:861-866

21. Inzucchi SE, Maggs DG, Spollett GR et al. (1998) Efficacy and metabolic effects of metformin and troglitazone in type II diabetes mellitus. N Engl J Med 338:867-872

22. Itoh Z (1997) Motilin and clinical application. Peptides 18:593-608

23. Tanaka T, Mizumoto A, Mochiki E, Suzuki H, Itoh Z, Omura S (1998) Effects of EM574 and cisapride on gastric contractile and emptying activity in normal and drug-induced gastroparesis in dogs. J Pharmacol Exp Ther 287: 712-719

24. Lebovitz HE, Feldman JM (1973) Pancreatic biogenic amines and insulin secretion in health and disease. Fed Proc 32:1797-1802

25. Coulie B, Tack J, Bouillon R, Peeters T, Janssens J (1998) 5- Hydroxytryptamine-1 receptor activation inhibits endocrine pancreatic secretion in humans. Am J Physiol 274: E317-E320

26. Yoshida N, Omoya H, Oka M, Furukawa K, Ito T, Karasawa T (1989) AS-4370, a novel gastrokinetic agent free of dopamine $\mathrm{D}_{2}$ receptor antagonist properties. Arch Int Pharmacodyn Ther 300:51-67

27. Watkins PB, Whitcomb RW (1998) Hepatic dysfunction associated with troglitazone. N Engl J Med 338:916-917 